\title{
Making Mitigation Meaningful to Descendant Communities: An Example from Zuni
}

\author{
Kurt E. Dongoske
}

\section{In memory of Cornell Tsalate, member of Brain Kiva, Eagle Down, and Ant Societies, and member of the Zuni Cultural Resource Advisory Team}

\section{ABSTRACT}

\begin{abstract}
Mitigation of adverse impacts to archaeological resources within cultural resource management (CRM) is commonly achieved through a data recovery plan. Under this venue, the primary significance of a given site is its evaluation under NRHP Criterion D-its information potential. Rarely is consideration given to the emotional, psychological, and spiritual values descendant Native American communities attribute to these places in relation to their importance under other criteria. The associative relationships and integrity of traditional religious and cultural practices connected to sites are often overlooked because the identification of significance and values of archaeological sites is defined by Euro-American intellectual and value-laden frameworks. Even if one claims "scientific objectivity" as one's guiding principle, implementation of such practices without regard for Native American perspectives are clear violations of NHPA mandates. Balanced design of mitigation measures is seriously lacking from CRM practice, resulting in descendant communities being continually disenfranchised through the silencing of their voice in the management of their own heritage and inheritance. This article examines this issue from the perspective of the Pueblo of Zuni and how Zuni successfully worked with the Bureau of Reclamation to design a strategy for resolving adverse effects that is meaningful and beneficial to the Zuni.
\end{abstract}

Keywords: mitigation, Zuni, traditional cultural properties, archaeological sites, Section 106, cultural resource management

La mitigación de los impactos adversos a los recursos arqueológicos dentro del manejo de los recursos culturales se logra comúnmente a través de un plan de recuperación de datos. Bajo este lugar, el significado principal de un sitio dado es su evaluación bajo el Criterio D del Registro Nacional de Lugares Históricos; Su potencial de información. En raras ocasiones, se da consideración a los valores emocionales, psicológicos y espirituales que las comunidades nativas americanas descendientes atribuyen a estos lugares al considerar su importancia bajo otros criterios. Las relaciones asociativas y la integridad de las prácticas religiosas y culturales tradicionales relacionadas con los sitios a menudo se pasan por alto porque la identificación de la importancia y los valores de los sitios arqueológicos están definidos por los marcos intelectuales y cargados de valores euroamericanos. Incluso si uno afirma que la "objetividad científica" es su principio rector, la implementación de tales prácticas sin tener en cuenta las perspectivas de los nativos americanos son violaciones claras de los mandatos de la Ley Nacional de Preservación Histórica. El diseño equilibrado de las medidas de mitigación carece seriamente de la práctica de CRM, lo que resulta en que las comunidades descendientes sean continuamente privadas de sus derechos mediante el silenciamiento de su voz en la gestión de su propia herencia y herencia. Este artículo examina este tema desde la perspectiva del Pueblo de Zuni y cómo Zuni trabajó con éxito con la Oficina de Reclamación para diseñar una estrategia para resolver los efectos adversos que sea significativa y beneficiosa para el Zuni.

Palabras clave: mitigación, Zuni, propiedades culturales tradicionales, sitios arqueológicos, Sección 106, gestión de recursos culturales

Well actually, when you come upon a [archaeological] site like this no matter who or where it is, you know, that it's a site there, for us Zunis, we say the people that were there have left; no, they have not spiritually, they are still there spiritually. They are still there so when we come upon a site before we set foot into that area, we greet them in Zuni. If it's in morning we would say. . . like "good morning." If it's evening or afternoon. We greet them because the spirits

Advances in Archaeological Practice 8(3), 2020, pp. 225-235

(c) The Author(s), 2020. Published by Cambridge University Press on behalf of Society for American Archaeology. This is an Open Access article, distributed under the terms of the Creative Commons Attribution licence (http://creativecommons.org/licenses/by/4.0/), which permits unrestricted re-use, distribution, and reproduction in any medium, provided the original work is properly cited.

DOI:10.1017/aap.2020.15 
have not left there; they're still there and that's how we Zunis understand the spirit world.-Presley Haskie (as quoted in Dongoske et al. 2019:449)

These places [archaeological sites] represent our lifeline; our trail. All of these sites had a purpose and a meaning. Seeing the physical traces of our past and our history is really meaningful. It gives us a sense of connection. The strength of Zuni knowledge and Zuni history is really reliant on our interaction with these places and with each other.Daniel Bowannie (as quoted in Dongoske et al. 2019:248)

And sometimes they [Zuni ancestors] leave that stuff along the way so if they leave those potteries, just leave them. If you find them just don't let them take anything because some people-archaeologists-take the potteries and get them to the museum, show it off. That's why we find our stuff that they take. Why do they take them to the museum? Just to show off what Zunis do? What their religion is? We don't want that. It's disrespectful because if they take them, they know that our ancestors, you know, they want it back because they don't want anybody to take their stuff. That's why we tell them not to take. It's disrespecting our ancestors because their [sic] taking away what they make, what they do. They just want to put in the museum to show it off and tell people that come when they ask questions about what they do, and they tell them. But we don't want to tell them what they do.-Shami Kanteena Jr. (as quoted in Dongoske et al. 2019:448)

Another word I despise to use is 'ruins.' By definition, ruin is defined as 1) a noun: The physical destruction or disintegration of something or the state of disintegration or being destroyed. Or 2) a verb: Reduce [a building or place] to a state of decay, collapse, or disintegration. Now, keeping those definitions (thanks to a quick Google search) in mind, sure, most ancient places have structures, monuments, castles, etc., that have seen better days. Keeping alive an ancient tale occupied with ancient techniques continues the path of wisdom and knowledge obtained through centuries, generation after generation. To imply that this continued practice of prayer, ceremonies, beliefs, no matter where the setting, recently inhabited or not, is false. We dwell upon the songs, stories, and work habits taught by the grandparents. And when we dwell in an area once walked by our ancestors, we humbly ask for permission to enter their dwelling.--Kevin Cooeyate (as quoted in Dongoske and Dongoske 2018:21-22)

\section{PLACES THAT CONNECT TO THE ANCESTORS}

The above statements characterize the deep emotional and psychological bonds that Zunis have to ancestral-including archaeological-sites and to their ancestors who continue to reside there. For Zunis, ancestral archaeological sites are tangible places of the past that provide them with knowledge, spiritual strength, sense of place, and grounding. According to Octavius Seowtewa, a member of the Zuni Cultural Resource Advisory Team, ancestral sites demonstrate that Zuni people are part of this land and material mediums through which they are "connected to our ancestors that passed away, through whose hearths we give them food offerings, and when we do find a hearth within a site, this is the place that we connect, this is the way we talk to our ancestors, this is why we ask our ancestors for help and this information is very important" (Seowtewa 2016:3).

Archaeological sites, including pictographs, petroglyphs, habitation sites, artifact scatters, special use areas, and other archaeological manifestations are physical signs created by Zuni ancestors documenting the Zuni emergence and subsequent migrations. As such, these sites are an inheritance imbued with great cultural and religious significance to the Zuni people. These places have never been abandoned, and they continue to maintain life through the presence of ancestral spiritual forces and function as places where contemporary Zunis communicate directly with the ancestors.

\section{MITIGATION: A PROBLEMATIC ISSUE}

When federal agencies consider resolving adverse effects under Section 106 of the National Historic Preservation Act (NHPA) to archaeological sites resulting from an undertaking through the design and implementation of an archaeological data recovery plan, these Zuni psychological and emotional associations are rarely considered. The principal focus of any archaeological data recovery plan is the retrieval of historic and scientific information contained within an archaeological site that might otherwise be lost or compromised. Under this emphasis, the primary importance of the site is its significance evaluation under Criterion $D$ of the National Register of Historic Places (NRHP), its potential to yield information about history or prehistory-a notion and concept of "information" that is limited to the narrow strictures of archaeological values and disciplining.

It is important to recognize that the privileging of this form of knowing and understanding and-even more fundamental to grasp-its intellectual and methodological application to Zuni and other Native cultural sites is nothing more than a reproduction and continuation of the archaeological discipline's promotion of heavily racialized, exclusionary, and limited representations of Indigenous culture and history. Since its disciplinary inception, the mainstream intellectual and methodological paradigms that have dominated archaeology have largely been constructed upon the narrow, limited, and indelibly entangled values, frameworks, and foundations of scientism and Western capitalist culture.

The consequence of such persevering colonialist attitudes as well as the privileging and applications of their associated values and worldview system in cultural resource management is that mitigation of adverse effects on "archaeological sites" is erroneously deemed routinely appropriate only through the development and execution of a data recovery research design. Most of these research designs not only do not but cannot meaningfully consider or integrate the psychological, emotional, or ideational perspectives of Native Americans-that is, the associative relationships and integrity of traditional religious and cultural practices connected to cultural sites-because such practices place both the identification of significance and values defining mitigation purely within Euro-American intellectual and value-laden frameworks. Importantly, even if one claims "scientific objectivity" as one's guiding principle, implementation of such practices are 
clear violations of the NHPA mandates and negligent in appropriately following the guidance of National Register Bulletin 38 regarding traditional cultural properties (TCPs).

TCPs, by their very definition, derive their significance from the role they play in a community's historically rooted beliefs, customs, and practices. For the Zuni people, archaeological sites are Register-eligible TCPs because they are tangible locations, or places, that are deemed real, actual, material, and physical, and that retain integrity. Bulletin 38 describes integrity as (1) sustained continuity between cultural practices, values, or beliefs and a place; and (2) largely intact place conditions that allow for significant cultural relationships and associations to endure (Parker and King 1998:17).

How, then, does one fulfill compliance responsibilities and approach matters of mitigation and resolution of adverse effects that are inclusive of Zuni relationships, values, and perspectives? By first and foremost absorbing, respecting, and enacting in good faith what Garroutte (2003:108) has described as "Radical Indigenism," which holds that "American Indian cultures contain tools of inquiry that create knowledge." And by this construction, one must respect and draw upon this knowledge as part of a process of learning about, thinking about, and living in the world. Traditional forms of knowing the world are rarely considered in the development of mitigation measures for archaeological sites. A recent review of numerous draft programmatic agreements designed as compliance for Section 106 that were submitted to the Pueblo of Zuni for review and comment by separate federal agencies validates their propensity to revert to archaeological data recovery as the only form of mitigating adverse effects. Not one of these draft programmatic agreements acknowledged or considered the associative values and traditional knowledge that the Zuni (or any other Native American tribe) ascribe to these historic properties.

This demonstrates that balanced design of mitigation measures is seriously lacking in the practice of cultural resource management, resulting in descendant Native American communities being routinely disenfranchised through the silencing of Indigenous voices in federal management decision-making that affects their heritage with a concomitant failure to recognize and acknowledge this very personal inheritance. Effective resolution of adverse effects must take into account the direct, indirect, and cumulative emotional, psychological, and spiritual impacts inflicted on descendant communities. This is not simply a value statement spoken from the position of my long-term experience and alliance with the Zuni people, but both as an ethical and professional imperative and a regulatory responsibility and requirement. As outlined under 36 CFR 800.2 and 800.4, respectively:

Indian tribes and Native Hawaiian organizations are recognized as possessing special expertise in assessing the eligibility of historic properties that may possess religious and cultural significance and that the lead agency officials shall ensure that Indian tribe[s] or Native Hawaiian organization[s] are provided a reasonable opportunity to identify [their] concerns about historic properties, advise on their identification and evaluation, including those of traditional religious and cultural importance, and articulate [their] views on the undertaking's effects on such properties, and participate in the resolution of adverse effects [Dongoske and Curti 2018:2].
Somewhat ironically, given what TCP significance is, it is only tribal positions and perspectives that can define what mitigation must take place to ensure that associative integrity to such places can endure. Consequently, neglect of this integrity has a twofold sociospatial and spatiotemporal effect. While mitigation is often filtered through a lens of the past, disenfranchisement is doubled not only in the present in relation to the development and implementation of supposed mitigation measures for places detached from their social, cultural, and spiritual contexts but also for the future, as capacities for associative integrity are eroded for future generations by the neglect and marginalization of tribal understandings and practices-of the very sociospatial connective tissues - of people-places and human-environment continuity.

\section{MEANINGFUL MITIGATION}

It is in this context that I wish to share a constructive example of a federal agency - the Bureau of Reclamation, Upper Colorado Region (hereafter Reclamation)—and the Pueblo of Zuni negotiating the design and implementation of a strategy for mitigating adverse effects to Zuni TCPs (ancestral archaeological sites) that were inclusive of Zuni psychological and emotional associated values, resulting in a relevant and meaningful product and outcome for the Zuni community.

\section{Place of Zuni Emergence}

The setting for this example is the Grand Canyon in northwestern Arizona. The Grand Canyon is the place where the Zunis emerged into the daylight of this world and began their migrations to find Idiwan'a (the "Middle Place"). Since that time, the Grand Canyon and the Colorado River have been sacred, and they figure prominently in Zuni cultural identity. According to Zuni narratives that describe the emergence of the Zuni people from Earth Mother's fourth womb, sacred items that identify the Zuni people-the Etdo:we (fetish bundles)—were the first to emerge. The people then came out into the sunlight world at a location at the bottom of the Grand Canyon near present-day Ribbon Falls (Figure 1).

The emergence narratives describe the Zunis' subsequent search for the center of the world, Idiwan'a. The Zuni people moved up the Colorado River and then up the Little Colorado River, periodically stopping and settling at locations along these rivers. At the confluence of the Little Colorado and the Zuni Rivers, many of the supernatural beings, or Koko, came into existence. After a long search, the Zunis located the middle of the world and settled there. The Middle Place is located in today's village of Zuni.

Today, the Zuni continue to maintain very strong cultural and spiritual ties to the Grand Canyon, Colorado River, and the Little Colorado River, which are facilitated through the umbilical connection of the Zuni River's confluence with the Little Colorado River and the Little Colorado River's confluence with the Colorado River in the Grand Canyon. Zuni religious beliefs, narratives, ceremonies, and prayers are intrinsically tied to the entire ecosystem of the Grand Canyon, which includes familial relationships the Zuni have with the birds, animals, soils, rocks, vegetation, and water. As a result of this spiritual umbilical connection, the Zuni people are concerned with activities that may affect resources in this sacred place. What happens in the Grand Canyon can and will have positive or negative impacts on the Zuni people in Zuni Pueblo. 


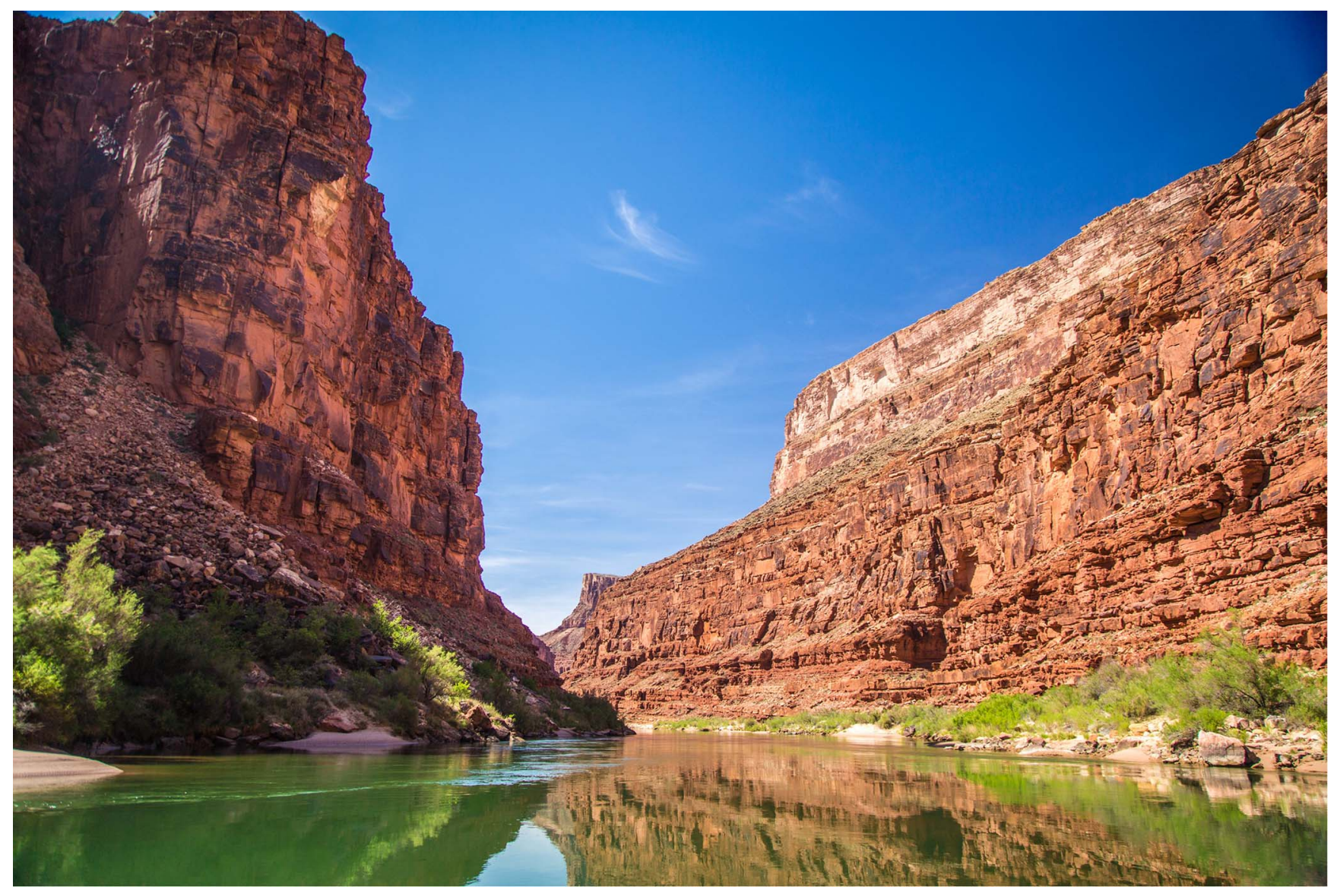

FIGURE 1. Grand Canyon. Photo courtesy of Daniel Byers, Skyship Films.

Ancestral (archaeological) sites located in the Grand Canyon are interconnected to one another by trails, and these trails connect the sites to the Zuni Pueblo. As such, the sites and trails act collectively as spiritual connections between Zuni ancestors and present-day Zunis, connecting the places that define and maintain the spiritual connection to the Zuni cultural landscape. The Pueblo of Zuni considers all ancestral archaeological sites to have the status of traditional cultural properties (TCPs) because these places are tangible monuments validating Zuni emergence and migrations that play fundamental roles in sustaining Zuni individual and collective cultural identities. Speaking about the importance of these sites in teaching Zuni children about their history, a Zuni cultural advisor, Daniel Bowannie, exclaimed, "Being born at Zuni Pueblo doesn't make you Zuni; it's all these old places. The same blood still runs through our veins. This is where our culture came from" (Dongoske et al. 2019:131).

Since the early 1990s, the Pueblo of Zuni has been actively engaged with the National Park Service (NPS), Reclamation, and other cooperating agencies in the development of the Glen Canyon Dam Environmental Impact Statement (GCDEIS). The GCDEIS was completed in 1995, and the transition to an adaptive management strategy for the operations of Glen Canyon Dam and the downstream natural and cultural resources was instituted through the 1996 Record of Decision (https://www.usbr.gov/uc/ envdocs/eis/gc/gcdOpsFEIS.html). The Glen Canyon Dam
Adaptive Management Program (GCDAMP) was established for the long-term preservation and management of the cultural and natural resources of the Grand Canyon in accord with the Grand Canyon Protection Act of 1992 (GCPA), the Endangered Species Act (ESA), and the NHPA of 1966, as amended (https://www.usbr. gov/uc/progact/amp/index.html\#background).

As a component of the GCDAMP, Reclamation is in an ongoing process of complying with Section 106 of the NHPA. Reclamation determined that its operation of Glen Canyon Dam is an undertaking (36 CFR 800.16y) that might result in changes to the character of downstream historic properties. To facilitate compliance, Reclamation, the Western and Rocky Mountain Regions of the NPS, the Advisory Council on Historic Preservation (ACHP), the Arizona State Historic Preservation Officer, the Hopi Tribe, the Hualapai Tribe, the Havasupai Tribe, the Navajo Nation, the Pueblo of Zuni, and the Southern Paiute Consortium entered into a programmatic agreement (PA) in 1994 (https://www.usbr.gov/uc/ envdocs/eis/gc/pdfs/Attach/attach2.pdf).

Throughout this process, the Pueblo of Zuni asserted to Reclamation that archaeological sites are eligible to the NRHP as Zuni historic properties with TCP significance per the definition provided by Parker and King (1998) in National Register Bulletin 38 (e.g., Dongoske et al. 1997; Ferguson et al. 1995:14-15). Specifically, these archaeological sites are considered eligible under 
Criterion A for the role they played in the Zuni migrations to find the Middle Place and under Criterion B because of the active role the Zuni ancestors continue to play in contemporary Zuni culture, identity, and history (as opposed to Criterion D, for "information potential"). From a Zuni perspective and through Zuni cultural practice, archaeological features are interrelated and cannot be understood without considering the greater social, cultural, geographical, and historical contexts in which they were and continue to be used. For example, shrines are related to springs, lithic tools are related to game, and villages are related to ancestral spirits (Dongoske and Nieto 2005). Zuni ancestral spirits continue to inhabit archaeological sites and provide guidance to Zuni people today. Ancestral sites with shrines are considered to be conduits between important deities and Zuni religious leaders, such as the A:shiwanne (Rain Priests), who make pilgrimages to leave offerings (Ferguson and Hart 1985:22; Hopkins 2014).

Since the early 1990s, Reclamation has worked with the NPS to mitigate the adverse effects on archaeological sites caused by the operations of Glen Canyon Dam. Throughout this period, the standard form of mitigation has been data recovery or the systematic collection of important scientific information recovered through archaeological excavation. As stated above, archaeological excavation as a form of mitigation only addresses the historic properties significance under Criterion D-its information potential—and does not sufficiently consider the Zuni psychological and emotional (associative) values ascribed to these sites as traditional cultural properties. For years, the Pueblo of Zuni requested greater and more meaningful representation and involvement in the development and implementation of mitigation strategies considered and authorized by Reclamation and the NPS.

The Pueblo of Zuni believes that the divide between Zunis and federal agencies in the consideration of adverse effects is due, in part, to a problematic overreliance on archaeological disciplinary perspectives and the resulting hegemony of archaeology in cultural resource management. Federal agencies typically view Zuni ancestral sites simply as archaeological sites. Consequently, these agencies think that adverse effects to these properties are only related to the loss of archaeological information and materials. Zuni people, however, understand their ancestral sites as active living places because they are the eternal homes of the Zuni ancestors that maintain heritage connections and spiritual vitality essential for the successful continuation and flourishing of Zuni culture. These archaeological sites are an inheritance that the Zuni people received from their ancestors who lived, loved, sacrificed, and endured pain and suffering to pass on their knowledge as well as material and embodied connections to this landscape as Zuni heritage. As such, contemporary Zuni people have a strong sense of stewardship to respect and honor their ongoing spiritual connection to their ancestors' spirits and to protect the eternal homes of their ancestors. Knowledge of their failure to protect the eternal homes of the ancestors creates deep psychological and emotional anguish for the Zuni people. This emotional distress is rarely, if ever, properly considered by a federal agency in the development of mitigation for an archaeological site.

This is not to suggest that the Zuni are against archaeological excavations. Archaeological excavation is considered necessary when an undertaking may completely destroy or seriously impact an archaeological site. One Zuni cultural advisor commented that archaeological investigations are a "better alternative than total destruction of a site, yet the impacts [from archaeological excavation] still constitute a huge loss to Zuni people" (Dongoske et al. 2019:167-168). Although archaeological excavations are not considered an acceptable form of mitigation (only avoidance is acceptable) from a Zuni perspective, the Zuni would like to have an opportunity to view recovered artifacts and other materials excavated from a site because "identifying artifacts will help Zuni children learn about Zuni history," as Seowtewa explained after viewing archaeological sites impacted by a construction project (Dongoske et al. 2019:251). From a Zuni perspective, archaeological excavation often results in the destruction of culturally significant sites affecting the loss of important information about Zuni history and concomitantly inflicts violence on the spiritual and emotional well-being of the Zuni people and their ancestors.

Moreover, the lack of Zuni cultural competency by archaeologists means that culturally important objects (artifacts) will not be identified properly and that they will most likely be discarded. For example, when the Zuni research team inspected LA 36578, a multicomponent site located in New Mexico along a water pipeline corridor of the Navajo Gallup Water Supply Project, archaeological data recovery excavations were in progress. Seowtewa identified several stone conglomerates, or concretions, in the "back dirt" pile-dirt that had been already sifted and discarded by archaeologists. He explained that these concretions are sacred items to Zuni. "They are ceremonial for Rain Priests and other religious practitioners-we put them in medicine water, and they signify that you will grow old as the rock" (Dongoske et al. 2019:89). The Zuni research team considered the concretions to be artifacts that had been deliberately brought to this site. The Zuni research participants were saddened that these items are often discarded by archaeologists and that they are not recognized as important and discussed in archaeological reports.

Historical narratives generated by archaeologists based on the analysis of the data recovered from archaeological excavation are often seen by Zunis as impersonal, written in the third person and less than meaningful to the Zuni people because they fail to acknowledge deep Zuni personal connections to their tangible heritage. In fact, the historical narratives generated by archaeologists are perceived by Zuni as unintentionally contributing to the further promotion of the erasure and denial of the unique Zuni history inscribed on this landscape through the continued favoring of a Euro-American perception of time, space, history, geography, and associated representations.

\section{Then, Now, and Forever: Zuni and the Grand Canyon}

After many years of conversation, Reclamation agreed in 2014 to fund a Zuni effort to video-document the importance of the Grand Canyon, Colorado River, and Zuni ancestral sites located in the Grand Canyon from a Zuni "emic" perspective as part of an educational program for use in the Zuni school systems. The inspiration for this project was in response to Zuni religious leaders' strong emotional comments after they experienced a Colorado River trip through the Grand Canyon. That experience was an overwhelming and positive affirmation of the Zuni connection to the Grand Canyon - a connection that they had heard about all their lives but had not experienced until that moment. 
Moreover, this emotional connection was so personally strong and life changing for each of them that they wished all Zunis could experience that trip through the Grand Canyon. They especially thought it was an important message for the Zuni youth. Knowing that it was not feasible for all Zunis to experience the Grand Canyon through a river trip, the Zuni religious leaders felt that a video documenting and demonstrating the experience would be meaningful in the Zuni community as a medium of conveyance.

The emotional and life-changing experience of having traveled the Colorado River through the Grand Canyon was recently expressed by a young Zuni man, Kevin Cooeyate. He stated:

As I sit and jot down many topics discussed in the river, I use the aid of photos captured, maps from Google and most importantly, the book A:shiwi A:wan Ulohnanne = The Zuni World. My emotions overwhelm me. I don't know why. Maybe because I'm thinking of our ancestors and what they had to endure in the Canyon. Maybe I feel a special bond with the artist described in the book (The Zuni World). Maybe I feel the urgency in keeping up with tradition. Maybe I ache because we have lost so much. As I think of the footsteps established in the Canyon, I also think of my grandfather specifically. Farlen Cooeyate once made a trip down the Canyon. Now I had a chance to walk those same footsteps and continue the legacy. One thing is for sure, I am a different person after this trip. My mind and heart were open throughout my life journey thus far. Within the 10 days in the Canyon, the ancestors transferred a bit of knowledge and wisdom in me but only as much as I can handle, of course. Now I see and feel the world differently. Let's just say, more appreciative [Dongoske and Dongoske 2018:35].

The objectives of this film project were envisioned as creatively, productively, and most importantly, appropriately achieving-in part-Reclamation's Section 106 responsibilities for mitigating adverse effects caused by operations of Glen Canyon Dam to Zuni traditional cultural properties in the Grand Canyon. This is because it also served as a mitigation measure that would be meaningful to the Zuni descendant community by addressing and connecting Zuni associative values to these places.

In 2015, Reclamation provided funding to the Zuni Cultural Resource Enterprise (ZCRE) for the purpose of implementing the Zuni Grand Canyon Film project (also known as the Zuni Associative Values Project). ZCRE shortly thereafter entered into a contractual relationship with Skyship Films, an independent film production company.

In January 2016, Daniel Byers, the director of Skyship Films, traveled to Zuni to work with the Zuni Cultural Resource Advisory Team (ZCRAT) and ZCRE in completing phase 1 of the project, which consisted of developing the film's storyboard, script, and shot location list (Figure 2). During this time, the central Zuni story and themes to be conveyed in the film were identified, discussed, and finalized collaboratively. Integration of the Zuni Map Art project was also determined appropriate, especially through the demonstration of the cultural contrast between a USGS topographic quadrangle or Cartesian representations of space with that of Zuni cultural understandings and practices of space.
The locations for filming were discussed and selected by the ZCRAT, both within the Grand Canyon and in significant locations (such as Hanłibinkya, Kołuwala:wa, Denatsali Im'a, and Chavez Pass) between Zuni Pueblo and the Grand Canyon that distinguish the Zuni cultural landscape. ZCRAT identified Zuni individuals to be interviewed and filmed, both on the river and at places between Zuni and the Grand Canyon.

Major film themes identified by the ZCRAT included the establishment of origins, in which Zunis assert their historic connections as an affirmation tool for their rightful place on the land. This connection is expressed as the Zuni being the first people in the Grand Canyon, which Zunis believe is substantiated by archaeological sites, petroglyphs, and pictographs there. Additionally, the Zuni hold that they are still in possession of material and spiritual artifacts from the Grand Canyon that were created soon after emergence.

Another theme identified was migrations. Emergence from Ribbon Falls is considered the Zuni point of origin. This is expressed and depicted throughout the Grand Canyon in petroglyphs and pictographs. Zuni ancestral sites represent the Zuni's migration to the Middle Place, with periodic stops along the way. Ancestral (archaeological) habitation sites and petroglyphs were left by Zuni ancestors to inform and educate their descendant children, contemporary Zunis, about the deep time Zuni connection to the Grand Canyon and the diverse landscape.

Stewardship and environmental ethics were also identified for inclusion in the Zuni film by presenting the Zuni relationship to the Grand Canyon as a very personal and mindful relationship, in which the land and all associated resources_animate and inanimate-should be treated with proper respect. The Zuni perceive lethal management actions that are still being considered and that have been implemented by federal agencies involving the extensive killing of non-native fish as an affront, a violation of Zuni environmental sensibilities, and a complete disregard for the sacredness of life.

The damming of rivers was another concern expressed by the Zuni religious leaders, especially the Colorado River, which was done without the federal government consulting the Zuni. As a result, this has damaged Zuni lives and livelihoods. Associated with the theme of rivers was water and springs. The Zuni believe that "nothing is stronger than water" and that water is life, an indelible part of a never-ending cycle of circulation from the sweat on one's brow to the clouds to the rain that nourishes the plants (Figure 3).

For the Zuni, the Colorado River is a TCP extending from the Green River in Wyoming to the Gulf of California. All the dams on the Colorado River and its tributaries adversely affect the river, which in turn negatively impacts the Zuni. Zuni cultural knowledge was a theme emphasized through the ways sacred plants, animals, minerals, and water from the Grand Canyon are all connected to Zuni ceremonial practice.

From a Zuni perspective, the spirits of Zuni ancestors often come back in the form of deer, elk, and bighorn sheep. When encountered in the Grand Canyon, these beings are greeted in the Zuni language. Eno:de is the Zuni word for "ancestor." Zuni ancestral sites in the Grand Canyon are often called by many EuroAmerican names, such as Fremont, Virgin Anasazi, Anasazi, and 


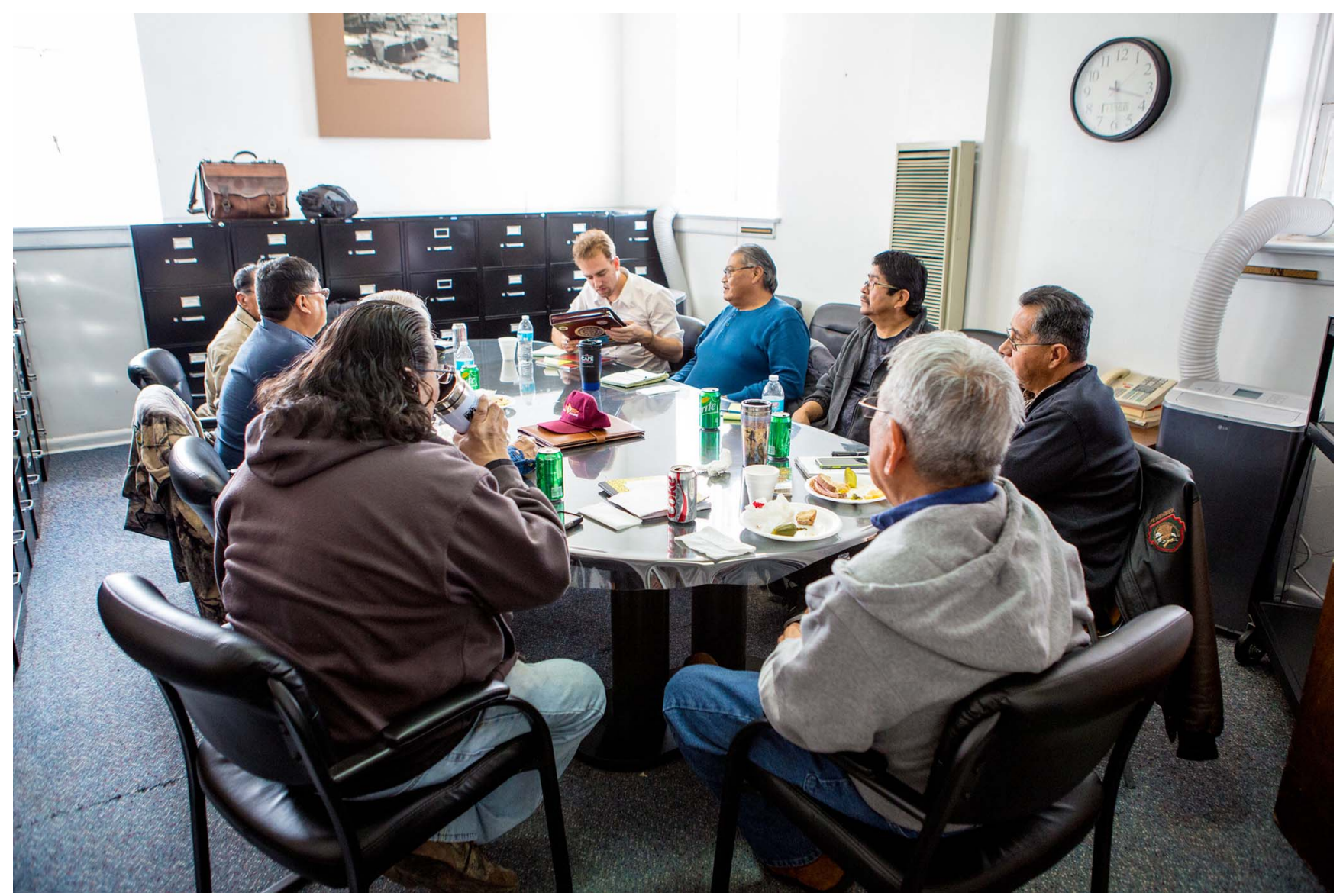

FIGURE 2. ZCRAT members discuss film themes with Daniel Byers of Skyship Films. From left to right around the table: Perry Tsadisai, Presley Haskie, Ronnie Cachini, Harry Chimoni, Octavius Seowtewa, Rayland Edaakie, Eldred Quam, and Daniel Byers. Photo by Kurt E. Dongoske.

Cohonino, but they are the Zuni ancestors, and Zunis hold that they should be respected and called by the correct Zuni word.

Finally, the theme of enduring Zuni ceremonies and living connections were emphasized to highlight the contemporary Zuni everlasting connection to the Grand Canyon since emergence-a connection that has never been broken despite unilateral actions by federal and state governments to restrict Zuni access. The Zuni religious leaders emphasized that non-Zuni people and federal agencies do not know about or appreciate these Zuni connections because they have ignored them in actions and policy. This film is viewed as a tool to educate and inform them, and hopefully, reinforce to the NPS the need for a Zuni perspective on how the Grand Canyon should be treated and managed.

The Zuni religious leaders wanted the main focus of the film to be the Zuni youth. The film will be used as a cultural and heritage educational tool. It can also be used to benefit many older Zuni people who have lost cultural knowledge.

The Zuni Colorado River filming trip occurred between April 20 and 29, 2016. Six Zuni religious leaders representing three medicine societies, five kiva groups, and the Rain priesthood participated in this river trip. The Zunis were accompanied by the Skyship film crew (Figure 4). Fourteen places along the Colorado River through the Grand Canyon were visited, and the Zuni religious leaders were recorded expressing their connections to, feelings for, and impressions of each place. The recording of these Zunis at these places helped facilitate the expression and the message that the Zuni wanted to communicate to the Zuni youth. Three days prior to launching on the Colorado River, the Zuni cultural advisors and the Skyship Film crew visited and recorded important Zuni traditional cultural places on the Zuni cultural landscape between the Pueblo of Zuni and the Grand Canyon.

Zuni artists and Zuni religious leaders participated in developing the film by producing paintings that were incorporated into the beginning of the film as animation and by narrating the film. Two versions of the film were produced: one completely in the A:Shiwi (Zuni) language and the other in English, with English subtitles during those scenes in which only A:Shiwi is spoken. The ZCRAT and the Zuni Tribal Council reviewed and approved a draft of the film before it was finalized, and a copy was provided to the Bureau of Reclamation as a contract deliverable. The film may be viewed at skyshipfilms.com/zuni.html. 


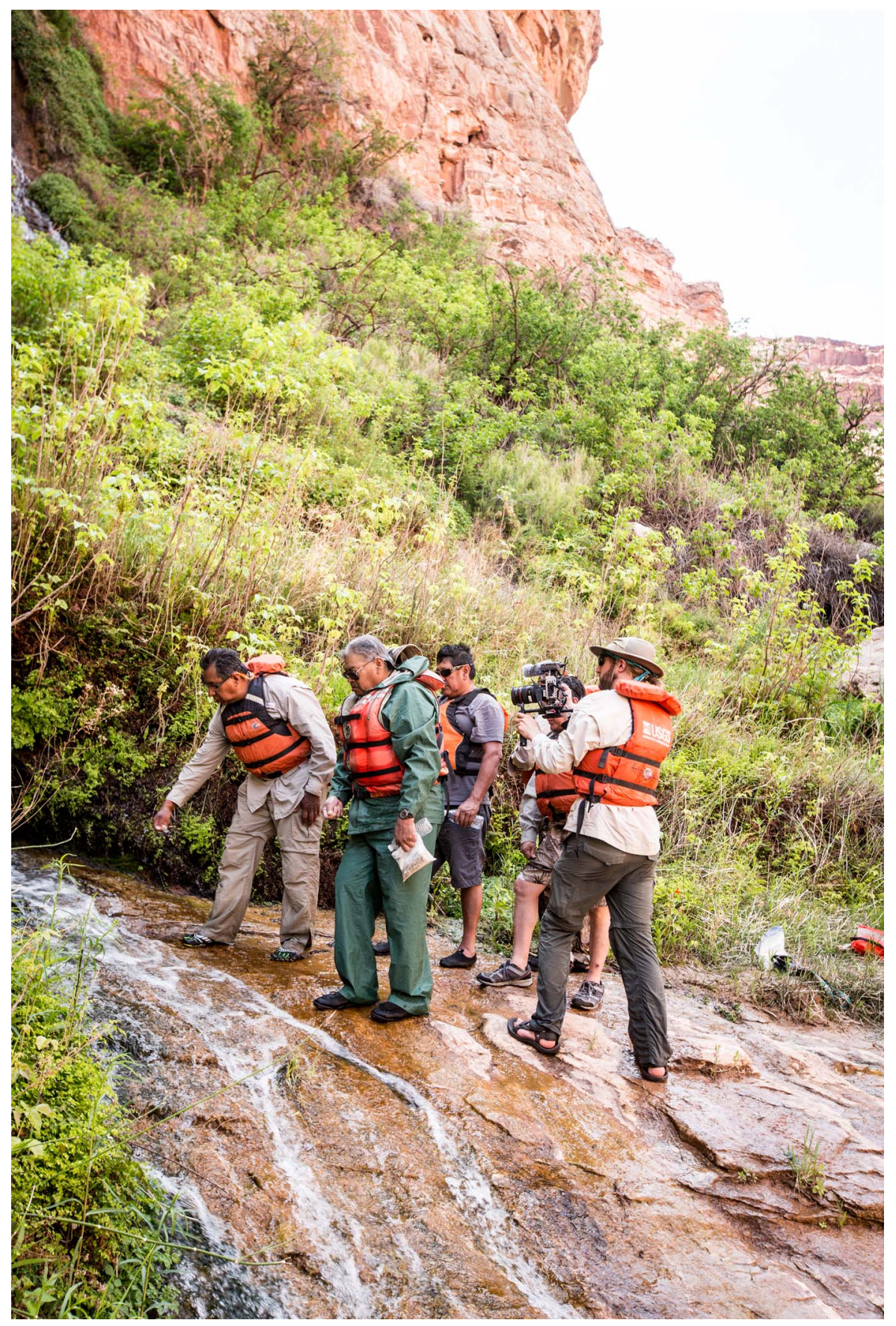

FIGURE 3. Zuni religious leaders and Sam Eilertsen at Vasey's Paradise. Photo courtesy of Daniel Byers.

The film, Lasapdayakya, La'gi, E Sha Małdeh A:Shiwi Lak Chimikyanakyadaya:Ah: Then, Now, and Forever: Zuni in Grand Canyon, publicly debuted at the January 2017 annual reporting meeting for the Glen Canyon Dam Adaptive Management Program in Phoenix, Arizona. DVD copies of the finalized film, both the A:Shiwi and English language versions, have been distributed to the Zuni Public School system for incorporation into its curriculum, to the Zuni Public Library, and to individual Zuni members who participated in the film's creation.
Since its completion, the Zuni film has been entered into film festivals, such as the Gallup Film Festival, where it won Best Language Preservation Film in 2017. That same year, it received Official Selection at the DC Environmental Film Festival (DCEFF), the Red Nation Film Festival (RNIFF), the Indigenous Film \& Arts Festival, and the Winnipeg Aboriginal Film Festival. It also received Official Selection at the Ancient Way Film Festival in 2019. Additionally, the film has had screenings at the Smithsonian National Museum of the American Indian and at Phillips Exeter Academy in Massachusetts on Martin Luther King Day. 


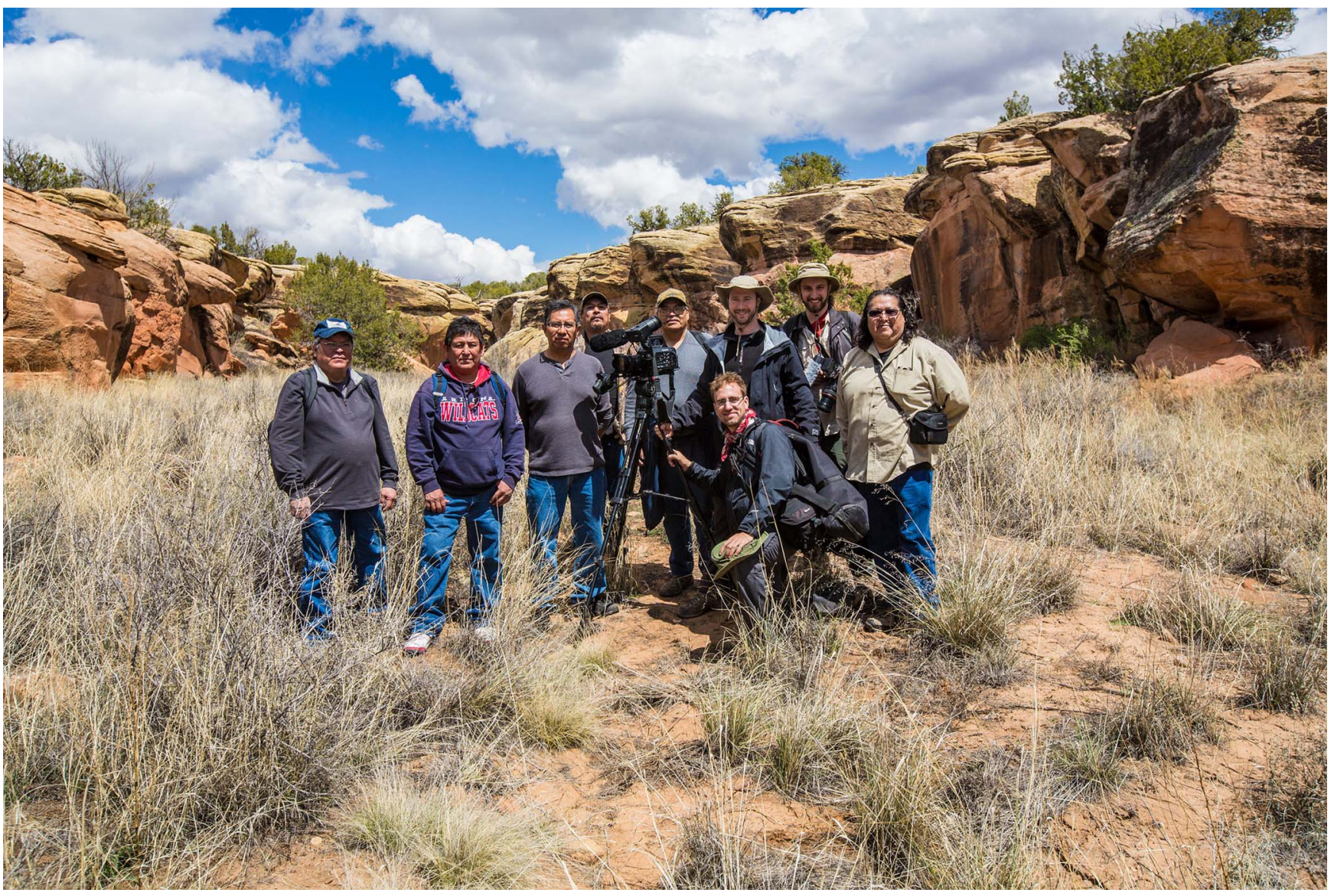

FIGURE 4. Zuni religious leaders and Skyship Films in Hanłibinkya. From left to right: Cornell Tsalate, Titus Ukestine, Octavius Seowtewa, Eugene Bowekaty, Eldred Quam, Zachary Ludeschar, Sam Eilertsen, Ronnie Cachini, and Daniel Byers (kneeling). Photo by Kurt E. Dongoske.

\section{CONCLUSION}

In 1966, when the National Historic Preservation Act became law, Congress found and declared that "the spirit and direction of the Nation are founded upon and reflected in its historic heritage" and that "the historical and cultural foundations of the Nation should be preserved as a living part of our community life and development in order to give a sense of orientation to the American people" (https://www.achp.gov/sites/default/files/201806/nhpa.pdf).

These poignant cultural and historical associations are at the heart of the Zuni people's relationship to their cultural landscape and their ancestors' eternal homes (archaeological sites). The embodied and what are often deemed intangible emotions, perspectives, and personal stewardship expressed by the Zuni in this film underscore (1) the importance of associative values inherent in the ongoing relationship of Zunis with tangible ancestral sites (historic properties) and their wider cultural landscape, and (2) how these values are often minimized, dismissed, or lost in the Section 106 mitigation process, which is designed principally through narrow and limited Western archaeological perspectives.
This is not to suggest that archaeological data recovery (scientific investigation) should not be part of mitigating adverse effects to archaeological sites. What is being advanced here is that it is not the only form of valid mitigation. Federal agencies should consider multiple associative values in addition to those values embodied in Criterion $D$ when treating archaeological sites. And in that process, they should consider and correspondingly integrate tribal traditional knowledge with an understanding of the past that is derived from archaeological research. As Kimmerer (2013) so eloquently demonstrates, traditional Indigenous knowledge and knowledge derived from the Western scientific tradition do not have to be at odds. In fact, they are often complementary and can, when treated commensurately, generate a more holistic and compassionate understanding of the environment and the human place in-and in relationship to-that environment.

The Zuni Grand Canyon Film project is an example of a successful form of mitigation that was negotiated between Reclamation and the Pueblo of Zuni because it contributed to Reclamation's compliance responsibilities as stipulated in the programmatic agreement: it directly addressed Zuni associative values by producing a beneficial outcome for the descendant community of 


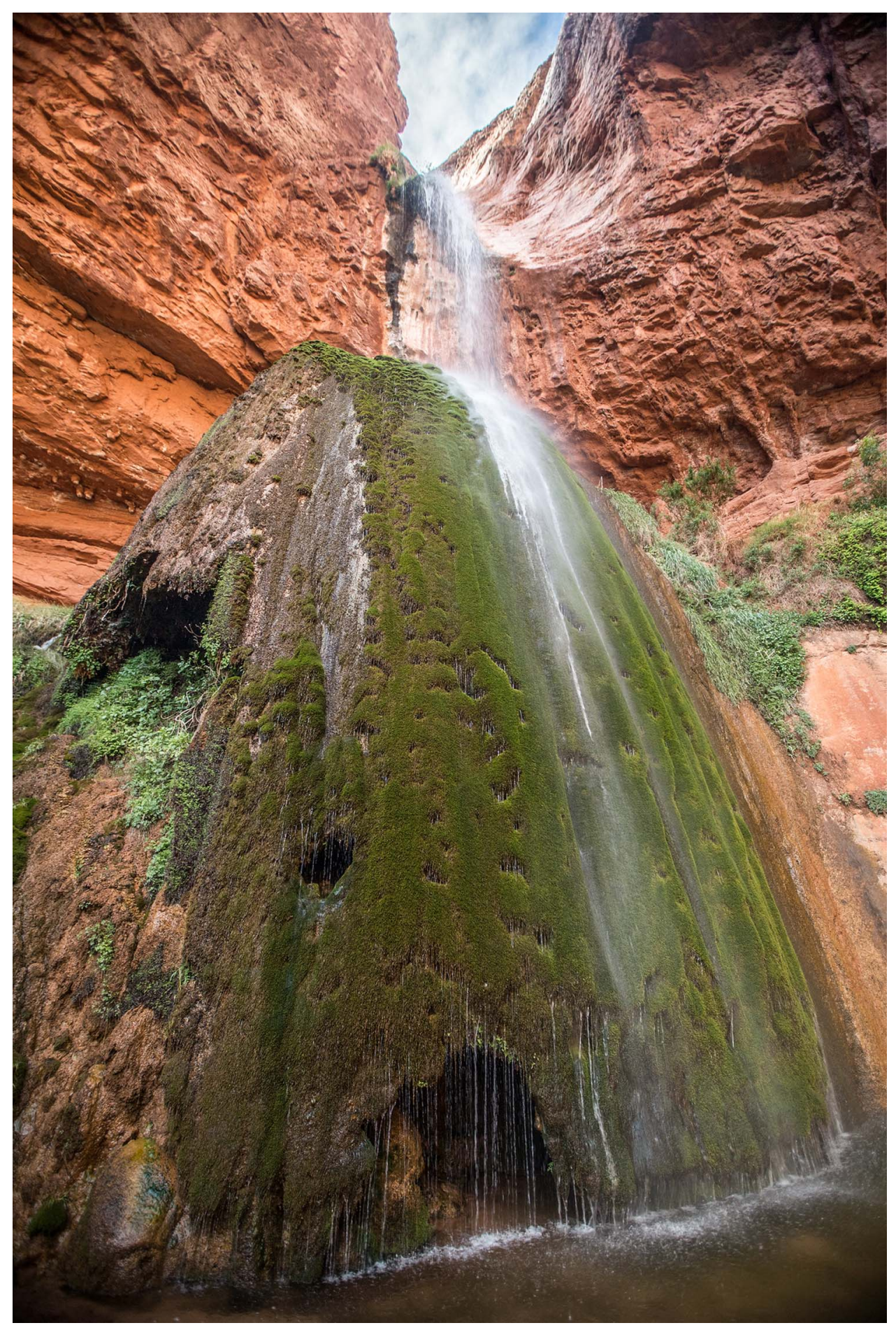

FIGURE 5. Ribbon Falls. Photo courtesy of Daniel Byers.

Zuni-an end product rarely realized by descendant communities in cultural resource management. The success of the film for the Zuni is attributed to the inspiration of the Zuni religious leaders and their desire for a product that benefits the Zuni, in combination with the sensitivity and artistic creativity of the Skyship Film director and crew to transform that inspiration into a short film (Figure 5).
Currently, the Pueblo of Zuni, Pueblo of Acoma, Pueblo of Jemez, Pueblo of Santa Ana, the Hopi Tribe, and the Navajo Nation are in a conversation with Reclamation regarding the development of collaborative forms of mitigation for the loss of connection(s) between cultural sites and San Juan Basin descendant communities for the Navajo Gallup Water Supply Project. Among the various forms of mitigation under consideration are a tribal youth education 
and participation program that seeks to help bridge a gap between tribal youth and elders; the creation of a traditional natural resource guidebook about the natural environment of the San Juan Basin, including plants, animals, minerals, and landscapes and landforms; and the production of an interpretive coloring book about tribal history and cultural connections to the San Juan Basin. The coloring book would be designed to incorporate images of the San Juan Basin in a pleasing way, on tribal terms, utilizing tribal language, as portrayed through tribal aesthetic sensibilities. The coloring book is seen as an effective means of sharing vital cultural and heritage information with both children and adults within a tribal community.

The long-term benefits to the descendant community of Zuni through the production of the Zuni Grand Canyon film will hopefully be realized for years and generations to come. For the Zuni, significant ancestral sites have been lost. Today, Zunis continue to deal with the adverse physical, spiritual, and emotional consequences caused by the displacement of their ancestors and the elimination of their historical imprint on the land through standard archaeological data recovery associated with development projects. As this article contends, only Zunis (descendant communities) can define what appropriate mitigation is from an associative integrity perspective. It is not only improper but disgraceful and disrespectful for federal agencies and/or archaeologists to dictate what mitigation measures ensure associative integrity. It is equally egregious for them to make an assessment of physical integrity without Zunis stating whether a given physical condition does or does not permit Zuni associative integrity to endure.

It is important that future mitigation development within cultural resource management give commensurate consideration to the associative values Indigenous people ascribe to traditional cultural properties, which are often archaeological sites.

\section{Acknowledgments}

I extend my sincere recognition and appreciation to Daniel Bowannie, Kevin Cooeyate, Presley Haskie, Shami Kanteena Jr., and Octavius Seowtewa for permitting me to use their voices in this article; only their voices make this article meaningful. I thank the Zuni Cultural Resource Advisory Team members for their review, approval, and support of this article's publication. To all of you, elahkwa! I extend my appreciation and gratitude to Daniel Byers, Sam Eilertsen, and Zachary Ludeschar of Skyship Films for your sensitivity and creativity in the production of this film. I appreciate the critical review and comments on earlier drafts of this article provided by Giorgio Hadi Curti, Kurt Anschuetz, John Douglass, and three anonymous reviewers. I also appreciate the open receptivity of the Bureau of Reclamation, Upper Colorado Region, to the concept of film as mitigation. Special recognition goes to Marianne Crawford, Contracting Officer for Technical Review, and Mary Barger, contract archaeologist, for identifying the funding and supporting this film effort. A shorter version of this article was presented in the session "Creative Mitigation Measures for the Section 106 and NEPA Process" organized by Shelby Manney and John G. Douglass. This article expands on an earlier article entitled "Re-Indigenizing Mitigation: Processes and the Productive Challenge to CRM," which was coauthored with Giorgio Hadi Curti and presented at the 2018 Society for American Archaeology meetings in Washington, DC.

\section{Data Availability Statement}

No original data were used in this article.

\section{NOTE}

1. The Zuni religious leaders (ZCRAT) discourage the use of the term "ruin." They prefer "ancestral site" or "Zuni (our) living history."

\section{REFERENCES CITED}

Dongoske, Kurt E., and Cindy Dongoske

2018 Pueblo of Zuni 2018 Cultural Resource Monitoring of the Colorado River Ecosystem through Grand Canyon: Zuni Youth Participation Trip. Report on file with the Zuni Cultural Resource Enterprise, Zuni, New Mexico.

Dongoske, Kurt E., and Giorgio Hadi Curti

2018 Re-Indigenizing Mitigation Processes and the Productive Challenge to CRM. Paper presented at the 83rd Annual Meeting of the Society for American Archaeology, Washington, DC.

Dongoske, Kurt E., Maren P. Hopkins, Michael C. Spears, and T. J. Ferguson 2019 Bishlankwin Ho'na:wan Ulohnanne (Our World to the North): Zuni Ethnographic Study for the Navajo Gallup Water Supply Project. Zuni Cultural Resource Enterprise Report No. 1350. Report on file at the Zuni Cultural Resource Enterprise, Zuni, New Mexico.

Dongoske, Kurt E. and Davis Nieto Jr.

2005 Anshe Ky'an'a: Zuni Traditional Places Located within the Fort Wingate Military Depot Activity, McKinley County, New Mexico. Report on file with the Zuni Cultural Resource Enterprise, Zuni, New Mexico.

Dongoske, Kurt E., Michael Yeatts, Roger Anyon, and T. J. Ferguson

1997 Archaeological Cultures and Cultural Affiliation: Hopi and Zuni Perspectives in the American Southwest. American Antiquity 62:600-608.

Ferguson, T. J., Kurt Dongoske, Michael Yeatts, and Leigh Jenkins

1995 Hopi Oral History and Archaeology, Part I: The Consultation Process. SAA Bulletin 13(3):12-15.

Ferguson, T. J., and E. Richard Hart

1985 A Zuni Atlas. University of Oklahoma Press, Norman.

Garroutte, Eva Marie

2003 Real Indians: Identity and the Survival of Native America. University of California Press, Berkeley.

Hopkins, Maren

2014 Heshoda Bitsulliya: Zuni Cultural Lifeways at Aztec Ruins National Monument and Chaco Culture National Historic Park. Anthropological Research LLC and Zuni Cultural Resource Advisory Team. Prepared for Office of Indian Affairs and American Culture, National Park Service, Denver, Colorado.

Kimmerer, Robin Wall

2013 Braiding Sweetgrass: Indigenous Wisdom, Scientific Knowledge, and the Teachings of Plants. Milkweed Editions, Minneapolis, Minnesota.

Parker, Patricia L., and Thomas F. King

1998 Guidelines for Evaluating and Documenting Traditional Cultural Properties. National Register Bulletin 38. U.S. Government Printing Office, Washington, DC

Seowtewa, Octavius

2016 Oral Interview Transcript. Manuscript on file, Zuni Cultural Resource Enterprise, New Mexico.

\section{AUTHOR INFORMATION}

Kurt E. Dongoske $\square$ Zuni Cultural Resource Enterprise, Pueblo of Zuni, PO Box 1149, Zuni, New Mexico 87237, USA (kdongoske@cableone.net, corresponding author) 